\title{
Identification of differentially expressed genes in chickens differing in muscle glycogen content and meat quality
}

\author{
Vonick Sibut ${ }^{1,2}$, Christelle Hennequet-Antier ${ }^{1}$, Elisabeth Le Bihan-Duval ${ }^{1}$, Sylvain Marthey ${ }^{3}$, Michel J Duclos ${ }^{1}$,
} Cécile Berri $^{1^{*}}$

\begin{abstract}
Background: The processing ability of poultry meat is highly related to its ultimate $\mathrm{pH}$, the latter being mainly determined by the amount of glycogen in the muscle at death. The genetic determinism of glycogen and related meat quality traits has been established in the chicken but the molecular mechanisms involved in variations in these traits remain to be fully described. In this study, Chicken Genome Arrays (20 K) were used to compare muscle gene expression profiles of chickens from Fat $(F)$ and Lean $(L)$ lines that exhibited high and low muscle glycogen content, respectively, and of individuals exhibiting extremely high (G+) or low (G-) muscle glycogen content originating from the $F_{2}$ cross between the Fat and Lean lines. Real-time RT-PCR was subsequently performed to validate the differential expression of genes either selected from the microarray analysis or whose function in regulating glycogen metabolism was well known.
\end{abstract}

Results: Among the genes found to be expressed in chicken P. major muscle, 197 and 254 transcripts appeared to be differentially expressed on microarrays for the F vs. L and the G+ vs. G- comparisons, respectively. Some involved particularly in lipid and carbohydrate metabolism were selected for further validation studies by real-time RT-PCR. We confirmed that, as in mammals, the down-regulation of CEBPB and RGS2 coincides with a decrease in peripheral adiposity in the chicken, but these genes are also suggested to affect muscle glycogen turnover through their role in the CAMP-dependent signalling pathway. Several other genes were suggested to have roles in the regulation of glycogen storage in chicken muscle. PDK4 may act as a glycogen sensor in muscle, UGDH may compete for glycogen synthesis by using UDP-glucose for glucoronidation, and PRKAB1, PRKAG2, and PHKD may impact on glycogen turnover in muscle, through AMP-activated signalling pathways.

Conclusions: This study is the first stage in the understanding of molecular mechanisms underlying variations in poultry meat quality. Large scale analyses are now required to validate the role of the genes identified and ultimately to find molecular markers that can be used for selection or to optimize rearing practices.

\section{Background}

With changes similar to those that occurred in the pig industry, the poultry market is now characterized by increasing diversity of processed products [1]. As a consequence, poultry companies are now involved in food technology and product development, and improvement of meat processing ability has become a prevalent concern. As in pigs, post-mortem $\mathrm{pH}$ is a key factor

\footnotetext{
* Correspondence: Cecile.Berri@tours.inra.fr

'INRA UR83 Recherches Avicoles, Institut National de la Recherche Agronomique, F-37380 Nouzilly, France

Full list of author information is available at the end of the article
}

controlling chicken meat quality [2]. Variations in ultimate meat $\mathrm{pH}(\mathrm{pHu})$ are responsible for variations in several breast meat properties, including water-holding capacity, colour and firmness [2,3]. Low ultimate $\mathrm{pH}$ results in "acid meat", with a pale aspect and reduced water-holding capacity [4], while high ultimate $\mathrm{pH}$ leads to DFD (dark, firm, dry) meat, dark in colour, with reduced shelf-life [5]. At the genetic level, there is a very strong negative correlation between the ultimate $\mathrm{pH}$ of breast meat and the level of muscle glycogen estimated by the glycolytic potential at the time of slaughter ( $\mathrm{rg}$ -0.97) [3]. The glycolytic potential has also been shown 
to be highly heritable $\left(\mathrm{h}^{2} 0.43\right)$ [3]. Understanding the mechanisms and identifying the genes controlling muscle glycogen storage constitute a promising way to increase control of and improve chicken breast meat properties. It would make it possible to develop useful breeding tools, such as molecular markers, to select birds with expected meat properties, and help optimize rearing practices, via the study of gene regulation.

Glycogen is the main metabolic fuel for the anaerobic glycolysis which takes place post-mortem when muscles are no longer supplied with oxygen. The genetic control of muscle glycogen, and therefore meat quality, was evidenced first in mammals and more recently in the chicken [3]. In mammalian species, including the pig, mouse and human, a major gene, PRKAG3 which encodes the $\gamma 3$ regulatory subunit of the AMP-activated protein kinase (AMPK), is responsible for variations in muscle glycogen content [6-10]. In the chicken, there is no information available suggesting that a major gene could be involved in the control of glycogen content in muscle. However, several studies have suggested that breast muscle glycogen content is related to growth and body composition: it decreases with growth rate and breast meat yield $[2,11]$ and increases with carcass fatness $[12,13]$.

The aim of the present study was to compare the expression profiles of muscles from chickens differing in muscle glycogen content and breast meat quality. In the first experiment, birds originating from two experimental lines (i.e. Fat (F) and Lean (L) lines) were compared. The $\mathrm{F}$ and $\mathrm{L}$ lines were originally divergently selected for and against the amount of abdominal fat [14] but they also exhibited differences in muscle glycogen content and in breast meat quality traits [13]. Despite a similar growth rate, the chickens from the $\mathrm{F}$ line were 3 times fattier than those from the L line. Moreover, due to high muscle glycogen content, the meat of the fat chickens exhibited a lower ultimate $\mathrm{pH}$ and higher drip loss and lightness than lean chickens. The differences in muscle glycogen between the $\mathrm{F}$ and $\mathrm{L}$ lines have been related to variations in mRNA encoding several enzymes regulating glycogen synthesis and degradation as well as in activation of AMPK by phosphorylation [13]. In the second experiment, the muscle transcriptomes were compared in individuals generated from the $F_{2}$ population produced from these two lines (i.e. $\mathrm{F}_{2} \mathrm{FL}$ ) and exhibiting extremely high (G+) or low (G-) muscle glycogen content. Individuals for this analysis were chosen according to their levels of glycogen in muscle, while differences in body fatness were much less pronounced than in the first model.

The use of a $20 \mathrm{~K}$ oligo microarray provided the first description of genes differentially expressed between breast muscles exhibiting high or low glycogen content, correlated with poor or high meat quality traits, respectively. This global approach was complemented by mRNA analyses on previously studied candidate genes [13] and on a subset of genes identified from array analysis. For genes with a human ortholog, further interpretation was based on the use of Ingenuity and Gene Ontology annotation databases highlighting several biological processes likely to be involved in muscle glycogen regulation.

\section{Results}

Carcass, muscle and meat quality traits of chickens used for gene expression analyses

The mean carcass and P. major muscle traits and SD are presented in Table 1. At 9 weeks of age, body weight was similar between $F$ and $L$ birds and between $\mathrm{G}+$ and G- birds generated from the $\mathrm{F}_{2} \mathrm{FL}$ population. Breast meat yield was slightly higher in $\mathrm{L}$ than in $\mathrm{F}$ birds and similar between G+ and G-. Abdominal fat yield was 2 -fold greater in $\mathrm{F}$ than in $\mathrm{L}$ birds while it was only $30 \%$ greater in G+ compared to G- birds. However, the muscle glycogen reserves were $61 \%$ higher in $\mathrm{G}+$ than in G- birds while they were only $34 \%$ higher in $F$ than in $\mathrm{L}$ birds. The ultimate $\mathrm{pH}$ of $\mathrm{P}$. major muscle of $\mathrm{F}$ and $\mathrm{G}+$, in relation to their greater glycogen content at the time of death, was higher than that of L and G- birds, respectively. The breast meat was lighter (greater $\mathrm{L}^{*}$ ) and less coloured (lower $\mathrm{a}^{*}$ and $\mathrm{b}^{*}$ ), and exhibited more drip loss in $\mathrm{F}$ than in $\mathrm{L}$ birds. Only meat lightness $\left(\mathrm{L}^{*}\right)$ was higher in $\mathrm{G}+$ than in $\mathrm{G}$ - birds generated from the $\mathrm{F}_{2} \mathrm{FL}$ population.

\section{Differential analysis on microarray}

Among the genes found to be expressed in chicken P. major muscle, 197 and 254 transcripts were differentially expressed between F and L and G+ and G-, respectively (Additional files 1 and 2). The gene expression foldchange ranged from 0.41 to 2.69 and 0.48 to 2.23 for the F vs. L and the G+ vs. G- comparisons, respectively. A trend was observed for a higher percentage of genes down-regulated in muscle with high glycogen content (57 and $60 \%$ in F and G+, respectively). Full details of gene name, function, accession number, fold-change and p-value for all differentially expressed transcripts are listed in additional files 1 and 2. Only 12 transcripts were recorded as differential in both analyses, i.e. $\mathrm{F}$ vs. $\mathrm{L}$ and G+ vs. G-, corresponding to 7 known genes (Additional file 3).

\section{Functional annotation}

Among the genes that were reported to be differentially expressed between muscles with high or low glycogen content, 337 with a human ortholog were submitted to annotation analyses. When compiling the lists of genes 
Table 1 Body weights and yields, and Pectoralis major muscle and meat quality traits of animals used for expression analyses

\begin{tabular}{|c|c|c|c|c|c|c|}
\hline & Fat & Lean & & G+ & G- & \\
\hline Chickens (n) & 8 & 8 & $p$ value & 8 & 8 & $p$ value \\
\hline \multicolumn{7}{|l|}{ Growth and body composition } \\
\hline Body Weight (g) & $1765 \pm 99$ & $1679 \pm 178$ & NS & $1891 \pm 226$ & $1979 \pm 195$ & NS \\
\hline Breast Yield (\%) & $12.4 \pm 0.7$ & $13.4 \pm 0.8$ & $<0.05$ & $12.0 \pm 0.9$ & $12.1 \pm 0.7$ & NS \\
\hline Abdominal Fat Yield (\%) & $5.2 \pm 0.9$ & $2.6 \pm 0.7$ & $<0.001$ & $3.8 \pm 0.7$ & $2.9 \pm 0.8$ & $<0.05$ \\
\hline \multicolumn{7}{|l|}{ Breast meat quality traits } \\
\hline Glycolytic Potential ( $\mu \mathrm{M} / \mathrm{g})$ & $122 \pm 8$ & $91 \pm 4$ & $<0.001$ & $126 \pm 9$ & $78 \pm 5$ & $<0.001$ \\
\hline Ultimate $\mathrm{pH}$ & $5.66 \pm 0.06$ & $5.86 \pm 0.08$ & $<0.001$ & $5.55 \pm 0.07$ & $5.88 \pm 0.07$ & $<0.001$ \\
\hline Lightness $\left(L^{*}\right)$ & $49.7 \pm 2.4$ & $43.96 \pm 2.1$ & $<0.001$ & $50.6 \pm 1.4$ & $48.3 \pm 1.7$ & $<0.01$ \\
\hline Redness $\left(a^{*}\right)$ & $-0.2 \pm 0.6$ & $1.7 \pm 0.6$ & $<0.001$ & $0.2 \pm 0.7$ & $0.4 \pm 1.6$ & NS \\
\hline Yellowness (b*) & $11.0 \pm 1.8$ & $12.6 \pm 0.9$ & $<0.05$ & $11.2 \pm 1.6$ & $11.4 \pm 2.0$ & NS \\
\hline Drip Loss (\%) & $1.7 \pm 0.7$ & $1.0 \pm 0.5$ & $<0.05$ & $1.2 \pm 0.65$ & $1.1 \pm 0.67$ & NS \\
\hline
\end{tabular}

The G+ and G- chickens were generated from the $\mathrm{F}_{2} \mathrm{FL}$ population produced from the 2 generation intercross between the founder Fat and Lean lines. The $\mathrm{G}$ - and $\mathrm{G}+$ chickens correspond to the individual females exhibiting the lowest and the highest muscle glycogen content within the $\mathrm{F}_{2} \mathrm{FL}$ population. NS = non-significant.

expressed differentially between G+ and G- and between $\mathrm{F}$ and $\mathrm{L}$ chickens, the software Ingenuity Analysis Pathways 7.0 (IPA, Ingenuity System ${ }^{\circledR}$, http://www.ingenuity. com) highlighted several biological functions (Table 2), including Lipid and Carbohydrate Metabolism. The genes associated with these two functions represent about $15 \%$ of the 337 genes considered for annotation analysis. When considering findings separately, IPA highlighted lipid metabolism and molecular transport as common pathways in the two models $(G+/ G-$ and $F / L)$ and also specific biological functions for each of them: Cell Morphology, Cell Cycle, and Cell to Cell Signalling and Interaction for F/L, and Small Molecular Biochemistry, Cell Death, and Cellular Development for G+/GGene Ontology (GO) terms are also widely used for global interpretation of the functions of genes revealed by differential microarray analysis. According to Gene Ontology, genes differentially expressed between $\mathrm{F}$ and $\mathrm{L}$ participated in several biological processes that can be grouped in 4 main biological functions: molecule transport and localization, and lipid, energy, and amino acid metabolism. Genes differentially expressed between G+ and G- belonged to biological processes especially related to lipid and energy metabolism, as well as developmental processes including cell growth, proliferation, differentiation and organization.

\section{Validation by real-time RT-PCR of a subset of genes revealed by differential microarray analysis}

The mRNA levels of 16 genes involved in Skeletal and Muscular System Development and Function, Lipid Metabolism or Carbohydrate Metabolism, and found to

Table 2 Relevant biological functions identified from the annotation analysis

\begin{tabular}{|c|c|c|}
\hline Category & P-value & Molecules \\
\hline Lipid Metabolism & $\begin{array}{l}9.42 \mathrm{E}-05- \\
2.56 \mathrm{E}-02\end{array}$ & $\begin{array}{l}\text { ABCA12, ABCA2, ABHD5, ACSBG2, ACSL1, ADF,ADIPOR2, ALDH1A1, AOX1,CD38, CEBPB,CETP, CTSS, DCl, } \\
\text { DRD3,GOT2, GRB10,HMGCL, HTT,INSIG1, LASS4, LPAR1,LPIN1,MTMR6, MTMR7,PCTP, PDK4,PHYH, PIK3CD, } \\
\text { PLA2G7, PNPLA2, PRKAG2, PSAP,RAB5A,SGPL1, SLC27A1,UCP3 }\end{array}$ \\
\hline Molecular Transport & $\begin{array}{l}9.42 \mathrm{E}-05- \\
1.93 \mathrm{E}-02\end{array}$ & $\begin{array}{l}\text { ABCA12, ABCA2, ABHD5, ACSL1, ADFP, ADIPOR2,ALDH1A1, ARNTL,CD38, CEBPB,CETP, CTSS, DCI,DRD3, F3, } \\
\text { GHR,GOT2,HCK, HTT,INSIG1, LASS4, LPAR1,LPIN1, NEB, P2RY2,PCTP, PIK3CD, PLN, PNPLA2, PSAP,SGK1, } \\
\text { SLC27A1,TGFB2, TGFB3,TRPC3, UCN3, UCP3, UGP2,VWF }\end{array}$ \\
\hline $\begin{array}{l}\text { Small Molecule } \\
\text { Biochemistry }\end{array}$ & $\begin{array}{l}9.42 \mathrm{E}-05-2.6 \mathrm{E}- \\
02\end{array}$ & $\begin{array}{l}\text { ABCA12,ABCA2, ABHD5, ACSBG2, ACSL1,ADAM10,ADFP,ADIPOR2,ALDH1A1, ALDH6A1, AOX1,CD38, } \\
\text { CEBPB,CETP, CTSS, DCI, DRD3,FOXO3, GHR,GLS,GOT2, GRB10,HMGCL,HTT,INSIG1, LASS4, LPAR1,MTMR6, } \\
\text { MTMR7, NUDT3,PCTP, PDK4, PIK3CD,PLA2G7, PNPLA2,LPIN1, PHYH, PRKAG2,PRPS1, PRPS2, PSAP,RAB5A, } \\
\text { RPIA,SGPL1, SLC27A1, TGFB2,TGFB3, UCN3, UCP3,UGDH,UGP2 }\end{array}$ \\
\hline $\begin{array}{l}\text { Carbohydrate } \\
\text { Metabolism }\end{array}$ & $\begin{array}{l}3.36 \mathrm{E}-04-2.6 \mathrm{E}- \\
02\end{array}$ & $\begin{array}{l}\text { ABHD5, ADAM10, ADIPOR2,ALDH2, CEBPB,CETP, FOXO3, GHR, HTT,IMPA2,MTMR6, MTMR7,PCTP, PDK4, } \\
\text { PIK3CD,PLA2G7, PRKAG2, PSAP,RAB5A, RPIA,SOCS3, TGFB2, TGFB3,UCN3, UCP3,UGDH, UGP2 }\end{array}$ \\
\hline Cell Death & $\begin{array}{l}3.36 \mathrm{E}-04- \\
2.64 \mathrm{E}-02\end{array}$ & $\begin{array}{l}\text { ALDH1A1, ATPA1, BAG3, CD99, CDK2AP1, CEBPB, CTSS, DAPK1, DCN, FGF1, FGFR2, FOXO3, GHR, HTT, } \\
\text { IL15, MCL1, NEFH, PAX5, PKN2, RGS4, SGK1, SGPL1, SIAH1, SPARC, SRF, TGFB2, TGFB3, TPM3 }\end{array}$ \\
\hline
\end{tabular}

The biological interpretation of expressional data was performed using Ingenuity Pathway Analysis 7.0 (IPA, Ingenuity Systems Inc., Redwood City, CA). The genes included in the analysis were shown to be differential between F and L and/or between G+ and G- by either microarray or real-time RT-PCR. Genes are presented in alphabetical order for each category. The genes over expressed in muscles with high ( $F$ or $G+)$ and low glycogen content ( $L$ and $G-)$ are in bold and normal characters, respectively. Genes in italic were differentially regulated between models (F vs. L or G+ vs. G-). 
be differential on microarray were further quantified by real-time RT-PCR in both models $(\mathrm{G}+/ \mathrm{G}$ - and $\mathrm{F} / \mathrm{L})$ (Table 3). The level of $18 \mathrm{~S}$ rRNA was chosen as reference and confirmed to be invariable. The expression levels (normalized to 18S) of genes were compared between G+ and G- and between F and L ( $\mathrm{n}=8$, same individuals used for microarray analyses) for each of the 16 genes selected. Ratios of gene expression determined by real-time RT-PCR were compared to ratios obtained using microarray analysis (Table 3). Over expression in G+ compared to G- was clearly confirmed for CEBPB and RGS2 ( $\mathrm{p} \leq 0.05$ ), and suggested for FOXO3 as similar fold-changes reached significance in the microarray analysis but not with real-time RT-PCR. Under expression was confirmed for LPAR1, PDK4, RPS6 and SRF ( $p \leq 0.05$ or $p \leq 0.10$ ), and suggested for PPP1R2B and UCP3, as similar fold-changes were observed in microarray and RT-PCR studies. None of the differences suggested between $\mathrm{F}$ and $\mathrm{L}$ chickens by the microarray study could be statistically confirmed by RT-PCR. Slightly higher expression of UGDH $(\mathrm{p} \leq 0.10)$ and lower expression of SRF ( $\mathrm{p} \leq 0.05)$ were suggested in $\mathrm{F}$ compared to $\mathrm{L}$ chickens. It is of note that the genes showed completely different variations between $\mathrm{F}$ and $\mathrm{L}$ and between G+ and G-. None of the 3 genes over expressed in G+ compared to G- (CEBPB, RGS2, FOXO3) differed between F and L chickens. Similarly, LPAR1 and RPS6, which were under expressed in G+ compared to G-, did not differ between $F$ and L. By contrast to what was observed when comparing $\mathrm{G}+$ to G-, PDK4 was over expressed in F compared to L, suggesting an inverse relationship between muscle glycogen and PDK4 expression in the two models. The observation of higher expression of ABHD5 in G+ compared to G- on microarray prompted real-time RT-PCR measurements in $\mathrm{F}$ and $\mathrm{L}$. While the differential expression between G+ and G- was not confirmed, significantly higher expression was observed in $\mathrm{F}$ compared to $\mathrm{L}$ chickens $(\mathrm{p} \leq 0.05)$. The biological interpretation of the real-time RT-PCR findings highlighted a gene network involved in several molecular and cellular functions, including lipid and carbohydrate metabolism, molecular transport, small molecule biochemistry, and cell morphology (Figure 1).

\section{Differential analysis of candidate genes}

The transcript expression of 14 genes (PRKAA1, PRKAA2, PRKAB1, PRKAB2, PRKAG1, PRKAG2, and

Table 3 Difference in mRNA levels between Fat (F) and Lean (L) and between G+ and G- muscles for genes chosen for quantification by real-time RT-PCR

\begin{tabular}{|c|c|c|c|c|c|}
\hline \multirow[t]{2}{*}{ Symbol } & \multirow[t]{2}{*}{ Name } & \multicolumn{2}{|c|}{ G+/G- } & \multicolumn{2}{|c|}{$\mathrm{F} / \mathrm{L}$} \\
\hline & & Microarray & qRT-PCR & Microarray & qRT-PCR \\
\hline \multicolumn{6}{|c|}{ Genes screened out from the microarray analyses } \\
\hline ABHD5 & Abhydrolase domain containing 5 & $1.367^{*}$ & 0.997 & NS & $1.527^{*}$ \\
\hline ACSL1 & Acyl-CoA synthetase long-chain family member 1 & $1.391^{*}$ & 0.994 & NS & 0.765 \\
\hline CEBPB & CCAAT/enhancer binding protein (C/EBP), beta & $1.491^{*}$ & $3.266^{* *}$ & NS & 0.828 \\
\hline ETFA & Electron-transfer-flavoprotein, alpha polypeptide & $0.719^{*}$ & 1.036 & $0.896^{*}$ & 0.896 \\
\hline $\mathrm{FOXO3}$ & Forkhead box $\mathrm{O} 3$ & $1.329^{*}$ & 1.400 & NS & 1.146 \\
\hline LPAR1 & Lysophosphatidic acid receptor 1 & $0.511^{*}$ & $0.472^{*}$ & NS & 1.243 \\
\hline PDK4 & Pyruvate dehydrogenase kinase, isozyme 4 & $0.645^{*}$ & $0.397 \dagger$ & ND & $3.007 \dagger$ \\
\hline PIK3CD & Phosphoinositide-3-kinase, catalytic, delta polypeptide & $1.768^{*}$ & 0.856 & NS & 1.613 \\
\hline PPP1R12B & Protein phosphatase 1 , regulatory (inhibitor) subunit $12 \mathrm{~B}$ & $0.758^{*}$ & 0.776 & NS & 1.103 \\
\hline RGS2 & Regulator of G-protein signaling 2 & $1.778^{*}$ & $2.433^{*}$ & $1.454^{*}$ & 0.821 \\
\hline RPIA & Ribose 5-phosphate isomerase A & $1.380^{*}$ & 0.945 & NS & 1.352 \\
\hline RPS6 & Ribosomal protein $\mathrm{S} 6$ & $0.611^{*}$ & $0.678+$ & NS & 1.014 \\
\hline SRF & Serum response factor (c-fos serum response element-binding transcription factor) & $0.562^{*}$ & $0.405^{*}$ & $0.734^{*}$ & 0.734 \\
\hline UCP3 & Uncoupling protein 3 (mitochondrial, proton carrier) & $0.641^{*}$ & 0.601 & NS & 0.731 \\
\hline UGDH & UDP-glucose dehydrogenase & NS & $0.503+$ & $1.441^{*}$ & 1.477 \\
\hline UGP2 & UDP-glucose pyrophosphorylase 2 & $1.469^{*}$ & 0.873 & NS & 0.898 \\
\hline \multicolumn{6}{|c|}{ Candidate genes chosen for targeted analyses by real-time $R T-P C R^{\S}$} \\
\hline PRKAB1 & AMP-activated, beta 1 non-catalytic subunit & ND & $0.603+$ & ND & 1.315 \\
\hline PRKAG2 & AMP-activated, gamma 2 non-catalytic subunit & ND & $0.517^{*}$ & ND & 1.129 \\
\hline PHKD & Phosphorylase kinase, delta & ND & $0.683^{*}$ & ND & 1.115 \\
\hline
\end{tabular}

For both microarray and real-time RT-PCR analyses, results are expressed as Fat to Lean and G+ to G- ratios of the expression gene. NS = non-significant; ND $=$ not determined. Statistical significance is indicated as follows: $\uparrow p$ value $<0.1,{ }^{*} p$ value $<0.05,{ }^{* *} p$ value $<0.01$. $\S$ Only genes identified as differentially expressed in at least one model are presented in the Table. 


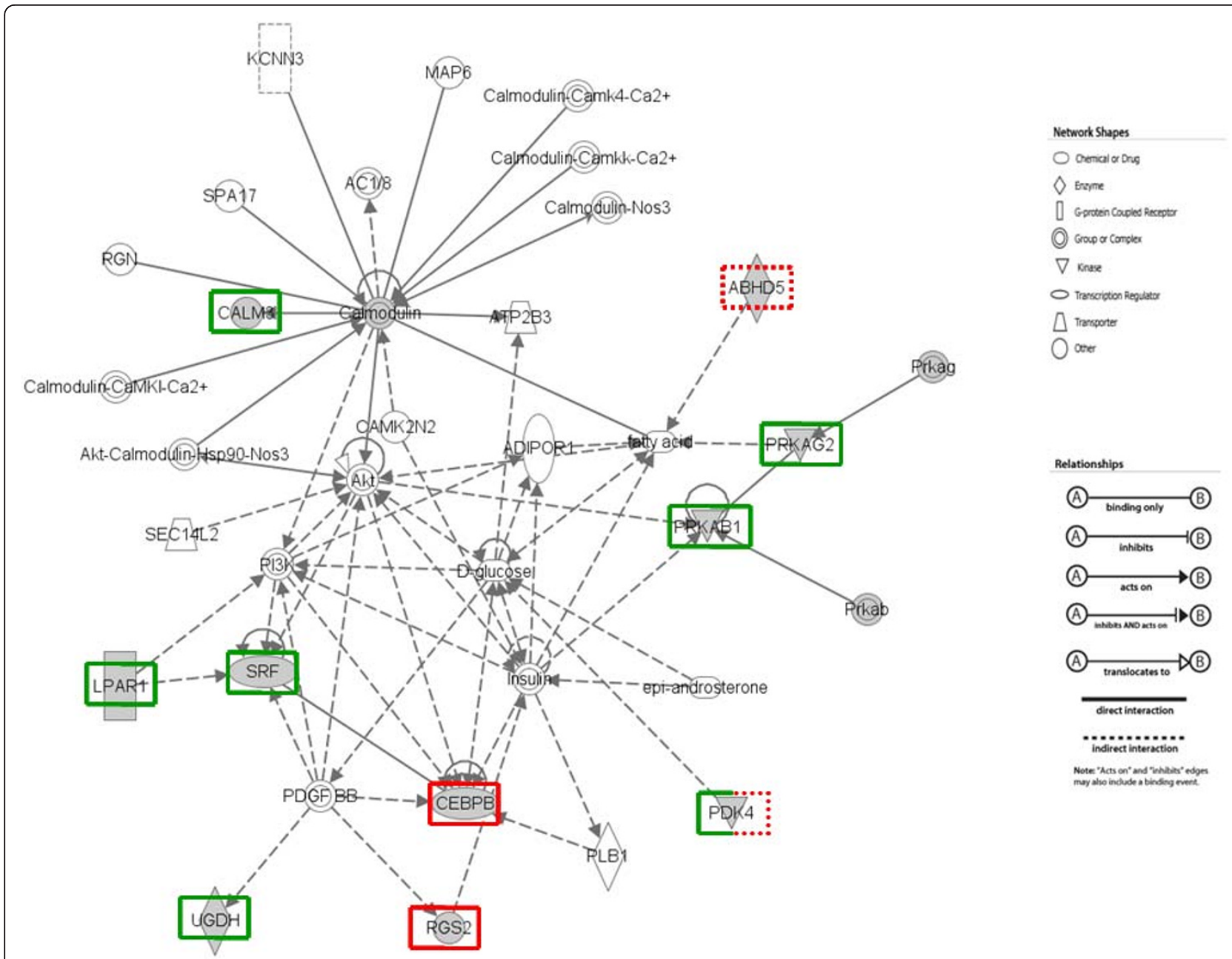

Figure 1 Network in which several genes identified as differential between Fat (F) and Lean (L) and/or G+ and G- muscles are involved. The biological interpretation of expression data was performed using Ingenuity Pathway Analysis 7.0 (IPA, Ingenuity Systems Inc., Redwood City, CA). The genes included in the analyses were shown to be differential between F and L and/or G+ and G-. This gene network is involved in several molecular and cellular functions including lipid and carbohydrate metabolism, molecular transport, small molecule biochemistry, and cell morphology. The differential genes surrounded by a dashed line originated from the comparison between $F$ and $L$ birds, and those surrounded by an unbroken line from the comparison between $\mathrm{G}+$ and $\mathrm{G}$ - muscles originating from the F2 cross between the $\mathrm{F}$ and $L$ lines. The genes over-expressed in muscles with high ( $F$ or $G+$ ) and low glycogen content $(L$ or $G-)$ are circled in red and green, respectively.

PRKAG3 encoding the AMP-activated protein kinase $\alpha 1, \alpha 2, \beta 1, \beta 2, \gamma 1, \gamma 2, \gamma 3$ subunits, respectively, GYS encoding muscle glycogen synthase, GSK3 encoding glycogen synthase kinase 3, PYG encoding glycogen phosphorylase, and PHKA PHKB, PHKD, and PHKG encoding the glycogen phosphorylase kinase $\alpha, \beta, \delta, \gamma$ subunits, respectively) directly involved in muscle glycogen turnover was quantified by real-time RT-PCR.

Only 3 of them were significantly differentially expressed between G+ and G- and their expression ratios are presented in Table 3 . None of the genes assayed was significantly differentially expressed between $\mathrm{F}$ and $\mathrm{L}$ chickens. The transcript levels of PRKAB1 and PRKAG2, which encode the AMP-activated protein kinase (AMPK) regulatory $\beta 1$ and $\gamma 2$ subunits, respectively was lower in G+ than in G- muscles: The ratio of $\mathrm{G}+/ \mathrm{G}$ - expression was $0.603(\mathrm{p}=0.07)$ for PRKAB1 and 0.517 for PRKAG2 $(\mathrm{p} \leq 0.05)$. The PHKD gene, which encodes the $\delta$ subunit of phosphorylase kinase (also referred as calmodulin), was also significantly downregulated ( $\mathrm{p} \leq 0.05)$ in $\mathrm{G}+$ compared to G- muscles, with a $\mathrm{G}+/ \mathrm{G}$ - expression ratio of 0.683 .

\section{Transcription factor analysis}

Transcription factor analysis highlighted several interrelations between genes whose expression differential was confirmed between G+ and G- animals by real-time RTPCR (Figure 2). Binding sites for the transcription factor 


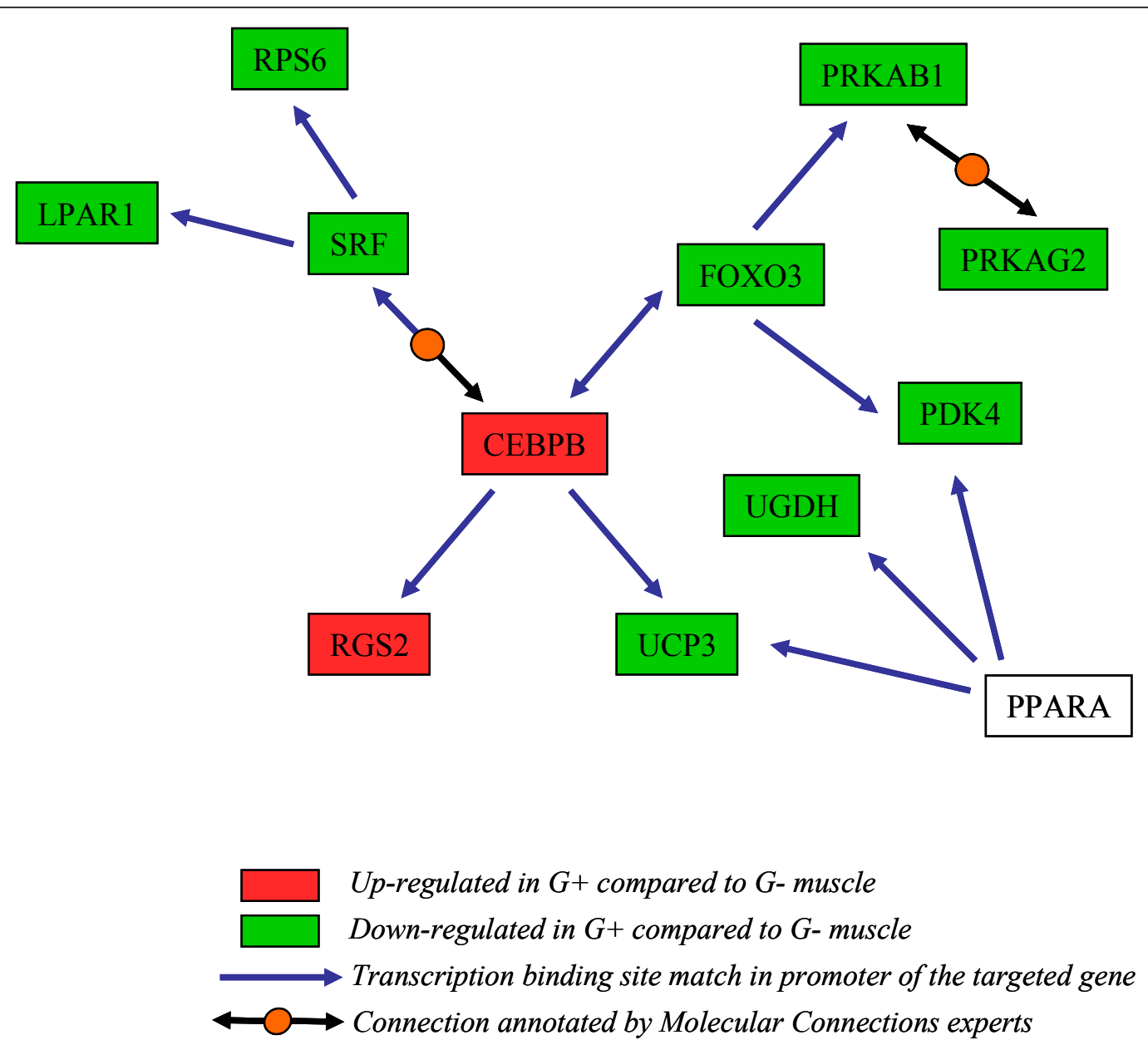

Figure 2 Summary of interactions between genes differentially expressed between G+ and G- muscles evidenced through a promoter analysis. Genes highlighted in red and green were up- and down-regulated in G+ compared to G- muscle, respectively. Gene names are indicated in capitals according to Gene Ontology. PPARA, Peroxisome proliferator-activated receptor alpha. Expression of PPARA was not measured in the present study. See Table 3 for other gene names.

CEBPB were thus reported in the promoters of RGS2, UCP3, SRF, FOXO3. Similarly, promoters of CEBPB, PRKAB1 and PDK4 possess the FOXO3 binding site, and RPS6 and LPAR1 possess binding sites for SRF. UGDH is under the control of PPARA (Peroxisome proliferator-activated receptor alpha) that also activates UCP3 and PDK4.

\section{Discussion}

Few studies have reported global gene expression surveys in the chicken to date. Moreover, our study is the first to relate global gene expression profiles to muscle glycogen content and variations in meat quality. In mammals, especially in cattle and the pig, several microarray studies have investigated global muscle gene expression in relation to sensorial meat attributes such as tenderness, juiciness, flavour and marbling, which are not directly related to muscle glycogen content [15-17].
Recent analyses in the pig helped to link gene expression profiles to variations in meat water loss, this characteristic being strongly related to variations in muscle $\mathrm{pH}$, but without considering glycogen variations in muscle [18]. The transcripts being up-regulated with high drip loss in the pig belong to groups of genes functionally categorized as genes of membrane proteins, signal transduction, cell communication, response to stimulus, and the cytoskeleton. Among genes down-regulated with high drip loss, functional groups of oxidoreductase activity, electron transport, and lipid metabolism were identified.

The originality of our study lies in the models chosen for microarray analyses. As already shown, there is a positive relationship between body fatness and glycogen content in breast muscle in the chicken [11-13]. Comparing divergently selected Fat and Lean chickens, which also differ in muscle glycogen content [13], is 
therefore relevant to identify mechanisms underlying variations in muscle glycogen directly related to variations in body fatness. It may however not be optimal for distinguishing the mechanisms involved in the control of adiposity and muscle glycogen metabolism. We therefore used chickens generated from a F2 cross between the Fat and Lean lines. In this population, phenotypically extreme individuals with high and low muscle glycogen content ( $+100 \%$ in G+ compared to G-) displayed only limited differences in abdominal fat content $(+30 \%$ in $\mathrm{G}+$ vs. G-). Being able to dissociate carcass fatness and muscle glycogen content highlighted that, although muscle glycogen metabolism and carcass adiposity are under the control of shared regulation in chicken, they also involve specific pathways. Working on F2 birds also allowed comparison of birds with a more homogeneous genetic background (due to two-generation crossing) while specifically differing in muscle glycogen content. Among the genes found to be expressed in chicken P. major muscle, 197 and 254 transcripts were differentially expressed between F and L and G+ and G-, respectively. Notably, only 12 transcripts, corresponding to 7 known genes, were recorded as differential in both models. With the hypothesis that the G+/G- model was the most powerful to identify genes controlling glycogen metabolism and to rule out the possibility that some of them could have been missed in the $\mathrm{F} / \mathrm{L}$ comparison, qRTPCR comparisons were conducted on both models and focused on genes linked to glycogen and lipid metabolism and differential between G+ and G-. The results confirm that the differences are indeed specific of the $G$ +/G- model for most genes (Table 3) and even for the genes showing a strong differential expression (CEBPB, LPAR1, RGS2, RPS6) no difference was observed between $\mathrm{F}$ and L. Moreover, the results also pointed out that PDK4 and UGDH were inversely regulated in relation to glycogen content in G+/G- compared to F/L. Similarly, we observed significant differences between $G$ + and G- and not between F and L for three candidate genes (PRKAB1, PRKAG2, PHKD). Altogether, the data further supported that the comparison of extreme animals with high or low glycogen in the F2 population was the most adapted to identify the mechanisms controlling glycogen metabolism in chicken muscle. For this reason we decided to further analyse 12 genes confirmed as differential between G+ and G-.

A bioinformatic analysis of the promoter sequences of these genes indicated a transcriptional link between 11 of them and suggested a key role for the three transcription factors, CEBPB, FOXO3, SRF as potential regulators of several functional candidates affecting glycogen turnover in the muscle (Figure 2). Figure 3 attempts to summarize how the differences observed at transcript level could impact on glycogen metabolism. The lower expression of UGDH (encoding UDP-glucose dehydrogenase) in the $\mathrm{G}+$ muscle is consistent with reduced conversion of UDP-glucose into UDP-glucuronate, and therefore higher use of glycogen synthesis. PHKD, that encodes the $\delta$ subunit of the phosphorylase kinase complex (PHK), was also expressed at lower levels in G+ muscle. This regulatory subunit (also referred to as calmodulin) contains the $\mathrm{Ca}^{2+}$-binding site which allows the activation of the phosphorylase kinase complex that both activates glycogenolysis and inhibits glycogen synthesis $[19,20]$. Its up-regulation in the G- muscle is therefore consistent with increased activity of the PHK complex and a reduced amount of glycogen in muscle. The activity of the PHK complex is under the control of both cAMP-dependent protein kinase (PKA) and AMPactivated protein kinase (AMPK). The nuclear transcription factor CCAAT/enhancer-binding protein beta $(\mathrm{CEBPB})$ and the regulator of $\mathrm{G}$ protein signalling 2 (RGS2) are involved in the control of the cellular cAMP level and therefore in the activation of cAMP-dependent protein kinase (PKA) [21-24]. PKA is known to suppress inhibition of the gamma subunit of phosphorylase kinase (PHK) and thereby activate the phosphorylase kinase enzyme complex, which in turn activates glycogen phosphorylase and inhibits glycogen synthase $[19,20]$. Our observations are therefore consistent with a potential role of CEBPB and RGS2 in the regulation of glycogen levels in chicken skeletal muscle, through the cAMPdependent PKA pathway. However, the LPAR1 gene (lysophosphatidic acid receptor 1), which exerts a similar effect on cAMP levels, showed different regulation, being down-regulated in $\mathrm{G}+$.

In the muscle of $\mathrm{G}+$ chickens, we observed lower expression of the gene encoding the regulatory $\gamma 2$ subunit of AMPK (PRKAG2). The AMP-dependence of the AMPK complex is markedly affected by the identity of the $\gamma$ isoform present, with $\gamma 2$-containing complexes having a greater response to AMP than those containing $\gamma 1$ or $\gamma 3$ [25]. Lower PRKAG2 mRNA levels in G+ muscles could imply a lower response of the AMPK complex to AMP, which in turn would be consistent with greater amounts of glycogen in muscle. Although the levels of AMPK activation were not measured in the present study, a reduced level of AMPK activation was previously reported in $\mathrm{F}$ compared to $\mathrm{L}$ chickens in conditions where PRKAG2 mRNA levels were lower in $F$ than in $\mathrm{L}$ [13]. The PRKAB1 gene encoding the regulatory $\beta 1$ subunit of AMPK was also expressed at lower levels in $\mathrm{G}+$ muscle, as previously described in [13] when comparing F and L chickens. The AMPK $\beta$ subunit contains a glycogen-binding site which allows the kinase to act as a glycogen sensor, AMPK activation being inhibited by glycogen [26]. How the changed expression of the $\beta 1$ regulatory subunit is related to 


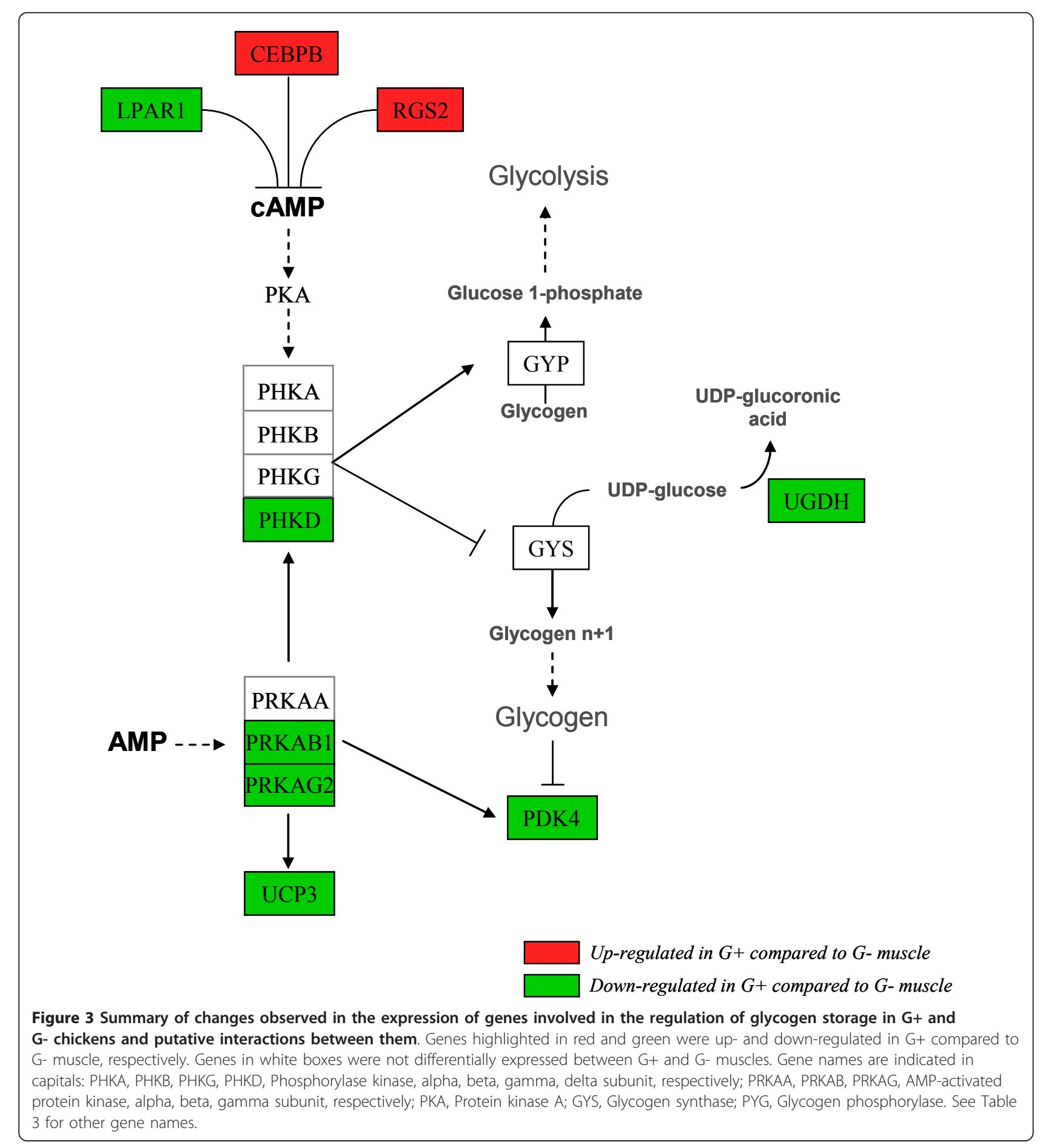

muscle glycogen content remains to be elucidated. While in the former study [13], PRKAB1, PRKAG2 and PHKD were relatively over expressed in the muscles of $\mathrm{L}$ compared to $\mathrm{F}$ chickens, none of them were found to be differentially expressed between $\mathrm{F}$ and $\mathrm{L}$ chickens in the present study. One explanation could be that the divergence in abdominal fatness was much more marked
(3 fold) between the Fat and Lean birds used in our previous study [13] than in those used in the present study ( 2 fold), possibly related to the composition of the diet. In fact, the birds used in the first experiment received a diet with a higher crude protein level than those used in the present study (19\% instead of $17 \%$ ) which might explain the lower adiposity differential between Fat and 
Lean lines reported here. It can be expected that more marked phenotypic differences could be related to more marked differences in gene expression.

A recent study [27] showed that AMPK activation combined with fatty acid administration synergistically induced pyruvate dehydrogenase kinase 4 (PDK4) expression, and in turn decreased cellular glucose oxidation. It can be expected that the preferential expression of the $\gamma 2$ AMPK subunit (implying potentially greater activation of the AMPK complex as discussed above) in the G- muscles is consistent with the increased expression of PDK4 reported in our study. AMPK activation also increases uncoupling protein 3 (UCP3) expression in muscles in mammals $[28,29]$. In chicken muscle, stimulation of AMPK is also associated with significant over expression of the avian UCP, the ortholog gene of mammalian UCP3 [30]. The relative down-regulation of the AMPK $\gamma 2$ subunit was thus consistent with that of UCP3 (or avUCP) reported concomitantly in $\mathrm{G}+$ muscle. As already mentioned, PDK4 was not downregulated by higher glycogen content in the muscle of the F line, but in contrast, up-regulated, suggesting a strong interaction with lipid metabolism, which could also result from the absence of regulation of AMPK subunits between $\mathrm{F}$ and $\mathrm{L}$ in the present study which contrasted with earlier results [13].

Several microarray studies conducted in genetically modified mice reported very distinct global gene expression profiles between animals exhibiting high or low glycogen content in muscle [31-33]. There are only a few common genes between those highlighted in our study and those demonstrated to be regulated in such models. This could arise from the fact that our birds were much less divergent in terms of glycogen content than the transgenic mice used previously, and also from the fact that different mechanisms may be involved. In mice, glycogen content was altered by invalidation or overexpression of genes directly controlling glycogen content such as GYS and PRKAG3. The study of Parker et al. (2006) [31] comparing mice lacking [32] or accumulating [33] glycogen in muscle, as a result of glycogen synthase (GYS) inactivation or overexpression, revealed marked differences in expression for a number of enzymes involved in the regulation of glycogen metabolism. Comparison of mutant and knockout mice for PRKAG3 showed that changes in the activity of the $\gamma 3$ subunit of AMPK were accompanied by coordinated and reciprocal regulation of carbohydrate and lipid metabolism [34]. Indeed, mutation 225Q (corresponding to the $\mathrm{RN}+$ allele gene identified in the pig [7]), which causes accumulation of glycogen in muscle, was associated with a gene expression profile suggesting increased glucose and lipid uptake, oxidative capacity and glycogen synthesis, and resistance of muscle to fatigue. Only slight disturbances in gene expression were observed between G+ and Gchickens, suggesting that the corresponding phenotypes resulted from the additive effects of several genes on the muscle glycogen in the chicken rather than a major effect of a single gene such as the RN gene in the pig [7]. The present study highlighted changes in several candidate genes directly involved in the control of glycogen metabolism such as PHKD, PRKAB1 \& G2 and PDK4 and also in genes involved in cAMP signalling such as CEBPB, RGS2 and LPAR1. These transcriptional candidate genes warrant further study in larger populations to correlate their expression with muscle glycogen levels, and to investigate the underlying mechanisms.

\section{Conclusions}

The aim of the study presented here was to identify candidate genes involved in the control of glycogen content in muscle. Studying phenotypically extreme chickens for muscle glycogen content generated from a F2 cross population helped to distinguish mechanisms involved in lipid and carbohydrate metabolism, which are highly related in the chicken. Several genes, related to carbohydrate metabolism or not, were suggested as potentially active in the regulation of muscle glycogen content and hence meat quality in the chicken. A QTL search is in progress on the F2 cross population used in the present study that aims to identify chromosomal regions involved in the control of phenotypes related to chicken meat quality, including muscle glycogen content. This should help to identify both functional and positional genes that could be subsequently included in large scale expression studies to validate the relationship between variations in gene expression and meat quality. These studies should together allow the identification of molecular markers that could be used to select birds with expected muscle and meat properties, and to optimize rearing practices via the study of gene regulation.

\section{Methods}

\section{Animals, Rearing and Slaughtering conditions}

Chickens were bred at INRA, UE1295 Pôle d'Expérimentation Avicole de Tours, F-37380 Nouzilly in accordance with European Union Guidelines for animal care and under authorization 37-112 delivered to C. Berri by the French Ministry of Agriculture.

The experimental Fat (F) and Lean (L) lines were generated from a composite meat-type strain of six different origins. F and L lines were divergently selected for abdominal fatness at 9 weeks of age over 7 generations, resulting in a wide difference in carcass fatness [13]. In the first experiment, 8 female chickens from each line were selected from a total of 72 broilers (36 F and $36 \mathrm{~L}$ ) for further gene expression profile analyses. Within the overall population, the breast muscle glycolytic potential 
was affected both by line ( $\mathrm{F}>\mathrm{L}$ line, $\mathrm{p}<0.01)$ and sex (female $>$ male, $\mathrm{p}<0.01$ ). Although no line/sex interaction was found, only females were included in microarray analysis to rule out any sex effect.

In the second experiment, the gene expression profiles of individuals generated from the F2 population produced from a 2 generation intercross between the founder F and L lines were compared. The F2 population consists of about 600 individuals produced from the cross of $5 \mathrm{~F} 1$ sires and $50 \mathrm{~F} 1$ dams. The 8 female chickens exhibiting the lowest (G-) and the 8 exhibiting the highest $(\mathrm{G}+)$ muscle glycogen content were used for microarray analysis.

In both experimental schemes, the birds were reared up to 9 weeks of age under regular conditions in a conventional poultry house. At 9 weeks of age and after 7 hours of feed withdrawal, the birds were slaughtered and processed at the experimental poultry unit as already described [2].

\section{Phenotypic traits}

Live body weight (BW), abdominal fat percentage and breast yield were measured in addition to ultimate meat $\mathrm{pH}$, meat colour at $24 \mathrm{~h}$ post-slaughter, and drip loss after two days of storage at $2^{\circ} \mathrm{C}$, as already described [2]. Meat colour was measured by the CIELAB trichromatic system as lightness $\left(\mathrm{L}^{*}\right)$, redness $\left(\mathrm{a}^{*}\right)$, and yellowness $\left(b^{*}\right)$ values. The glycolytic potential (GP) was determined according to Dalrymple and Hamm [35], from $1 \mathrm{~g}$ of muscle tissue collected $15 \mathrm{~min}$. post-slaughter and immediately frozen in liquid nitrogen and calculated as described in Sibut et al. [13].

\section{RNA isolation}

Total RNA was extracted from P. major muscle samples rapidly frozen in liquid nitrogen after death using the Qiagen RNeasy Midi Kit (Qiagen, Courtaboeuf, France), according to the manufacturer's instructions. Concentration and quality of extracted RNA were assessed using a Nanodrop 1000 spectrophotometer (Nanodrop Technol$\mathrm{ogy}^{\circledR}$, Wilmington, DE) and a 2100 Bioanalyser (Agilent Technologies, Massy, France), respectively.

\section{Oligo design and array spotting}

The Chicken $20 \mathrm{~K}$ Array was obtained from CRB GADIE (INRA Jouy en Josas; http://crb-gadie.inra.fr). The array design has been published in Gene Expression Omnibus with the platform name GPL8199 [36]. The Chicken 20K Oligo set was produced from 20,460 oligonucleotides (60 to 75 nucleotides) designed using the OligoArray 2.0 software against the chicken ENSEMBL transcripts. The transcripts were selected from the chicken genome draft available in December 2004 and extensive matching of the UMIST and DT40 full length
EST's with the TIGR clusters (http://chick.umist.ac.uk/). Oligos from a $20 \mathrm{~K}$ set were arrayed by Operon in 384well V-bottomed plates (Genetix). Each well contained $1 \mathrm{nmol}$ of oligo. They were resuspended in water on Staccato RapidPlate (Caliper). Spotting was performed on glass slides (Corning, Ultragaps), with 48 Stealth 3 Microspotting pins on Chipwriter (Virtek), with control of humidity (45-50\%). After the print run was completed, oligo plates were covered with seals and deep frozen at $-20^{\circ} \mathrm{C}$ in a protected environment. The arrays produced contained exactly the 20,460 oligonucleotides from the original set, 442 buffer spots and 218 unusable oligos (internal control from Opéron). On this array batch, three were used for batch quality control validation: arrays were controlled by SybrGreen to check the presence, intensity and overall shape of the spots and the lack of signal in negative controls (buffer). A lot is considered validated when $95 \%$ of observed signals appear where an oligo is expected and if no signal appears in the negative controls.

\section{Annotation}

Because the $20 \mathrm{~K}$ oligonucleotide set was defined in 2004 from heterogeneous data sources, the quality of the previously designed oligonucleotides was checked, comparing them with the chromosomes of the 2.1 Washington University assembly of the chicken sequence genome [37]. The comparison was made using NCBI Blast with a $75 \%$ similarity threshold over 50 base pairs. The transcripts were then retrieved for each high scoring pair (HSP) corresponding to the location using the Ensembl API (version 3 Ensembl 52). An oligonucleotide had to be in a single gene (even if it was spanning 2 exons) to be selected for further analyses. The corresponding annotations were then retrieved from Ensembl using the Blast HSP coordinates. Among the 20,460 gene-oligonucleotides, 12,907 were identified as aligning with a single coding region in the chicken genome sequence (Version 3.2, February 2009). As an Ensembl gene name and/or a GO biological process term for only $32 \%$ of the 12,907 oligo subset were retrieved, it was decided to rely on human orthologs (according to the "one to one" criteria of ENSEMBL annotation) which could be identified for $94 \%$ of the 12,907 oligonucleotides, making it possible to retrieve HGNC-HUGO gene symbols for the majority of them $(75 \%$ of $94 \%$ of 12,907$)$. The annotations obtained by a bioinformatics procedure developed by SIGENAE (INRA) are available on the web site: http://www.sigenae. org [37].

\section{Microarray procedure mRNA labelling and hybridization}

Fifty $\mu \mathrm{g}$ of each RNA sample were reverse-transcribed and labelled with Alexa fluorescent-dyes using the 
SuperScript ${ }^{\mathrm{TM}}$ PlusIndirect cDNA Labelling System (Invitrogen, Cergy-Pontoise, France), according to the manufacturer's instructions. A dye-switch procedure was used by labelling $\mathrm{F}$ and $\mathrm{L}$ or $\mathrm{G}+$ and $\mathrm{G}$ - individuals alternately with Alexa 555 green dye and Alexa 647 red dye (Molecular Probes, Invitrogen). After purification, the labelled cDNA samples were quantified using the NanoDrop in order to define the dye concentration and the Frequency Of Incorporation (FOI) which was calculated as follows: FOI (Dye/1000 bases) = Dye $(\mathrm{pmol}) /$ cDNA (ng) * 324.5 (pg/mol). According to the manufacturer, the optimal FOI should be between 20 and 50 dye-labelled nucleotides per 1000 nucleotides. The slides were dynamically hybridized at $42^{\circ} \mathrm{C}$ for $16 \mathrm{~h}$ in 30 to $40 \mu \mathrm{l}$ of buffer (PRONTO!, Corning, Life Sciences ) containing 30 to 50 pmoles of each dye using the SlideBooster (Olympus Advalytix, Germany). Microarrays were then washed with the AdvaWash (Olympus Advalytix, Germany). We finally obtained an initial subset of 8 microarrays for each paired sample from $\mathrm{F}$ and $\mathrm{L}$ chickens, and a second subset of 8 microarrays for each paired sample from G+ and G-. In all cases, hybridizations were performed with a balanced block design (i.e. half of the samples were labelled with Alexa 555 and the other half with Alexa 647 for each condition). The fluorescence ratio for each gene reflected the relative abundance of the mRNA of interest of either $F$ to $L$ or G+ to G- chickens.

\section{Data acquisition}

Detection of the fluorescence signals was performed with a laser scanner (GenePix 4000B from Axon Instrument, CA) keeping a constant PMT gain for each channel. Image analysis was performed with GenepixPro 6.0 software (Axon instruments, Inc., Union City, CA) [38]. Raw data files for each array containing all measured values were stored in GenePix files and analysed with the Anapuce 2.0 package (http://cran.r-project.org/web/ packages/anapuce/index.html) [39] developed in R language. This package contains functions for the normalization and the analysis of data.

\section{Filtering and data normalization}

For the normalization step, data were first filtered according to the genepix flag criterion automatically performed by GenepixPro 6.0 [38]. Spots were then discarded in cases of lack of fluorescence homogeneity or overlapping with a contiguous spot. The homogeneity of the background and the fluorescence intensity was systematically checked on each microarray by the boxplot and image plot functions of the $\mathrm{R}$ package.

The Alexa 647/Alexa 555 ratio used for analysis was expressed as the $\log 2$ of the ratio of median pixel intensity of the two red and green channels. Log2 median ratio values were then normalized on each individual array according to the hypothesis that the majority of gene expressions do not differ between two samples. Normalization was performed by global loess and block effect correction via subtraction of the median per block using the Anapuce 2.0 package [39].

\section{Data deposition}

The microarray data were deposited in the Gene Expression Omnibus (GEO) public repository http://www.ncbi. nlm.nih.gov/geo The accession numbers for the series are GSE17428 and GSE17445, and the sample series can be retrieved with accession numbers GSM434777 to GSM434784 and GSM435103 to GSM435110. The sample series for each microarray contains the raw data (median signal) of each Alexa637 and Alexa555 channel as well as the normalized data (log2 (Alexa637/Alexa555 ratio)).

\section{Data analysis}

To identify genes differentially expressed between $F$ and L and G+ and G- chickens we used the DiffAnalysis functions of Anapuce 2.0 under the R statistical environment. Because of the high test numbers, corresponding to the number of genes tested, the raw $\mathrm{p}$ value of each gene was adjusted according to the Benjamini-Hochberg method controlling the false discovery rate [40]. Difference in gene expression was judged significant if its adjusted $\mathrm{p}$ value was $\mathrm{p}<0.05$.

\section{Real-time RT-PCR assay}

Five $\mu$ g of each RNA sample were reverse-transcribed using RNase $\mathrm{H}^{-}$MMLV reverse transcriptase (Superscript II, Invitrogen, Illkirch, France) and random primers (Promega, Charbonnières les Bains, France). A $1 / 50$ or $1 / 100$ dilution of RT reaction, corresponding to 50 or 100 ng RNA equivalent, was then used for realtime quantitative PCR. cDNA samples were mixed with the SYBR Green I qPCR Master Mix Plus (Eurogentec, Angers, France) and specific reverse and forward primers. Primers are described in additional file 4 for genes originating from the microarray analyses and in [13] for candidate genes (PRKAA1, PRKAA2, PRKAB1, PRKAB2, PRKAG1, PRKAG2, and PRKAG3 encoding the AMP-activated protein kinase $\alpha 1, \alpha 2, \beta 1, \beta 2, \gamma 1, \gamma 2$, $\gamma 3$ subunits, respectively, GYS encoding muscle glycogen synthase, GSK3 coding glycogen synthase kinase 3, PYG encoding glycogen phosphorylase, PHKA, PHKB, PHKD, and PHKG encoding the glycogen phosphorylase kinase $\alpha, \beta, \delta, \gamma$ subunits, respectively). The level of $18 \mathrm{~S}$ ribosomal RNA (18S) chosen as a reference was determined with the TaqMan Universal qPCR Master Mix Kit and a pre-developed Taqman assay reagent (Applied Biosystems). Reaction mixtures were incubated in an ABI PRISM 7000 apparatus (Applied Biosystems, Courtaboeuf, France) programmed to conduct one cycle $\left(95^{\circ} \mathrm{C}\right.$ for $10 \mathrm{~min})$ and 40 cycles $\left(15 \mathrm{~s}\right.$ at $95^{\circ} \mathrm{C}$ and $1 \mathrm{~min}$ at $60^{\circ} \mathrm{C}, 62^{\circ} \mathrm{C}$ or $64^{\circ} \mathrm{C}$ according to the gene) [13]. For 
reactions using SYBR Green, a melting curve programme was then performed to check the presence of a single product with a specific melting temperature. Amplification products were checked by electrophoresis and further sequenced. PCR runs for each sample were performed in triplicate. Each PCR run included a notemplate control and triplicates of control, i.e. a pool of 12 cDNA samples (i.e. 6 for high and 6 for low GP condition). The calculation of absolute mRNA levels was based on the PCR efficacy and the threshold cycle (CT) deviation of an unknown cDNA versus the control cDNA according to the equation proposed by Pfaffl [41] and as already described [42]. For all genes under study and for $18 \mathrm{~S}$, the amplification rates were in the range of $99 \%$ to $100 \%$ and could be considered as equal to 1 . For the same sample, the gene expression level could thus be normalized in relation to the $18 \mathrm{~S}$ expression level.

\section{Functional annotation and promoter analysis}

The biological interpretation of expressional data was performed using Ingenuity Pathway Analysis 7.0 (IPA, Ingenuity Systems Inc., Redwood City, CA) and Gene Ontology (GO, http://www.geneontology.org/). The genes included in the analyses were shown to be differentially expressed (microarray or real-time RT-PCR) between F and L, G+ and G- or both. For the genes validated as differentially expressed between G+ and G-, analysis of promoters was performed by using the MatInspector and Eldorado applications of Genomatix (http://www.genomatix.de) $[43,44]$.

\section{Additional material}

Additional file 1: Genes differentially expressed between Fat and Lean chickens. Results were expressed as the Fat to Lean ratio of the gene expression. The $p$ value of each gene was adjusted according to the Benjamini-Hochberg method controlling the False Discovery Rate [40]. Difference in gene expression was considered significant if its adjusted $p$ value was $p<0.05$.

Additional file 2: Genes differentially expressed between the G+ and $\mathrm{G}$ - chickens generated from the $\mathrm{F}_{2} \mathrm{FL}$ population. Results were expressed as $\mathrm{G}+$ to $\mathrm{G}$ - ratio of the gene expression. The $p$ value of each gene was corrected according to the Benjamini-Hochberg method controlling the False Discovery Rate [40]. Difference in gene expression was considered significant if its adjusted $p$ value was $p<0.05$.

Additional file 3: List of the common genes that were differentially expressed in the two models (Fat vs. Lean chickens and G+ vs. Gchickens generated from the $F_{2} \mathrm{FL}$ population).

Additional file 4: Selected real-time RT-PCR primer sequences and accession numbers.

\section{Abbreviations}

$a^{*}$ : redness; ABHD5: Abhydrolase domain containing 5; ACSL1: Acyl-CoA synthetase long-chain family family member 1; AMPK: AMP-activated protein kinase; b*: yellowness; BW: Body Weight; CEBPB: CCAAT/enhancer binding protein beta; DFD: Dry, Firm and Dry; LPAR1: Endothelial differentiation lysophosphatidic acid G-protein-coupled receptor 2; ETFA: Electron transfer flavoprotein subunit alpha mitochondrial precursor; FDR: False Discovery Rate; GP: Glycolytic Potential; FOI: Frequency of Incorporation; FOXO3: Forkhead protein; GSK3: Glycogen Synthase Kinase 3; GYS: Glycogen Synthase; HGNC: HUGO Gene Nomenclature Committee; HSP: high scoring pair; IPA: Ingenuity Pathway Analysis; L*: lightness; PDK4: Pyruvate dehydrogenase kinase isozyme 4; PHKA: Glycogen Phosphorylase Kinase subunit alpha; PHKB: Glycogen Phosphorylase Kinase subunit beta; PHKD: Glycogen Phosphorylase Kinase subunit delta; PHKG: Glycogen Phosphorylase Kinase subunit gamma; pHu: ultimate pH; PIK3CD: Phosphoinositide-3-kinase catalytic delta polypepetide; PMT: PhotoMultiplier Tube; PPP1R12B: Myosin light chain phosphatase small subunit major isoform; PRKAA1: AMP-activated protein kinase subunit alpha 1; PRKAA2: AMP-activated protein kinase subunit alpha 2; PRKAB1: AMP-activated protein kinase subunit beta 1; PRKAB2: AMP-activated protein kinase subunit beta 2; PRKAG1: AMP-activated protein kinase subunit gamma 1; PRKAG2: AMP-activated protein kinase subunit gamma 2; PRKAG3: AMP-activated protein kinase subunit gamma 3; PYG: Glycogen Phosphorylase; real-time RTPCR: real-time Reverse Transcription-Polymerase Chain Reaction; SRF: Serum response factor; RGS2: Regulator of G-protein signalling 2; RPIA: Ribose 5phosphate isomerase A; RPS6: Ribosomal protein; UCP3: Uncoupling protein 3 (mitochondrial proton carrier); UGDH: UDP-glucose dehydrogenase; UGP2: UDP-glucose pyrophosphorylase 2.

\section{Acknowledgements}

This research program was supported by a grant from the ANR-Genanimal Program (France). VS was supported by a grant from CIFRE (France). The authors thank the staff of the breeding facilities (INRA, UE1295 Pôle d'Expérimentation Avicole de Tours, Nouzilly, France) and laboratory (INRA, UR83 Recherches Avicoles, Nouzilly, France) for their technical assistance. The authors also thank Aurélien Brionne for his technical help in the development of hybridization procedures and in the automation of annotation, Philippe Bardou from SIGENAE for his help in the depositing of data in the public repository Gene Expression Omnibus, CRB-GADIE for supplying the microarrays, and Dr Sandrine Lagarrigue for annotation analyses.

\section{Author details}

${ }^{1}$ INRA UR83 Recherches Avicoles, Institut National de la Recherche Agronomique, F-37380 Nouzilly, France. 'Institut Technique de l'Aviculture, Centre INRA de Tours, F-37380 Nouzilly, France. ${ }^{3}$ INRA Centre de Ressources Biologiques des Animaux Domestiques et d'Intérêt Economique, Institut National de la Recherche Agronomique, F-78352 Jouy en Josas Cedex, France.

\section{Authors' contributions}

VS carried out the gene expression, annotation and statistical analyses and drafted the manuscript. CHA supervised the statistical analyses. CB supervised the study. CB, MJD, and EBD participated in the design of the study, the phenotype data collection and helped to draft the manuscript. SM contributed to the creation of microarrays. All authors read and approved the final manuscript.

Received: 28 June 2010 Accepted: 16 February 2011

Published: 16 February 2011

\section{References}

1. Mead GC: Meat Quality and consumer requirements. In Poultry Meat Processing and Quality. Edited by: GC Mead. CRC Press, Boca Raton, FL (USA), Woodhead Publishing Ltd, Cambridge, England; 2004:1-18.

2. Berri C, Le Bihan-Duval E, Debut M, Santé-Lhoutellier V, Baéza E, Gigaud V, Jégo $Y$, Duclos MJ: Consequence of muscle hypertrophy on characteristics of Pectoralis major muscle and breast meat quality of broiler chickens. J. Anim. Sci 2007, 85:2005-2011.

3. Le Bihan-Duval E, Debut M, Berri C, Sellier N, Santé-Lhoutellier $V$, Jégo $Y$, Beaumont C: Chicken meat quality: genetic variability and relationship with growth and muscle characteristics. BMC Genetics 2008, 9:53.

4. Barbut S: Problem of pale soft exudative meat in broiler chickens. $\mathrm{Br}$. Poult. Sci 1997, 38(4):335-358

5. Allen CD, Russell SM, Fletcher DL: The relationship of broiler breast meat color and $\mathrm{pH}$ to shelf-life and odor development. Poult. Sci 1997, 76(7):1042-1046. 
6. Ciobanu D, Bastiaansen J, Malek M, Helm J, Woollard J, Plastow G, Rothschild M: Evidence for new alleles in the protein kinase adenosine monophosphate-activated gamma(3)-subunit gene associated with low glycogen content in pig skeletal muscle and improved meat quality. Genetics 2001, 159(3):1151-1162.

7. Milan D, Jeon JT, Looft C, Amarger V, Robic A, Thelander M, RogelGaillard C, Paul S, lannuccelli N, Rask L, Ronne H, Lundström K, Reinsch N, Gellin J, Kalm E, Le Roy P, Chardon P, Andersson L: A mutation in PRKAG3 associated with excess glycogen content in pig skeletal muscle. Science 2000, 288:1248-1251

8. Andersson L: Identification and characterization of AMPK $ү 3$ mutations in the pig. Biochem. Soc. Trans 2003, 31:232-235.

9. Barnes BR, Marklund S, Steiler TL, Walter M, Hjälm G, Amarger V Mahlapuu M, Leng Y, Johansson C, Galuska D, Lindgren K, Abrink M, Stapleton D, Zierath JR, Andersson L: The 5'-AMP-activated protein kinase gamma3 isoform has a key role in carbohydrate and lipid metabolism in glycolytic skeletal muscle. J Biol Chem 2004, 279(37):38441-7.

10. Costford SR, Kavaslar N, Ahituv N, Chaudhry SN, Schackwitz WS, Dent R, Pennacchio LA, McPherson R, Harper ME: Gain-of-function R225W mutation in human AMPK gamma(3) causing increased glycogen and decreased triglyceride in skeletal muscle. PLOS One 2007, 2(9):e903.

11. Berri C, Wacrenier N, Millet N, Le Bihan-Duval E: Effect of selection for improved body composition on muscle and meat characteristics of broilers from experimental and commercial lines. Poult. Sci 2001, 80:833-838.

12. Le Bihan-Duval E, Berri C, Baéza E, Millet N, Beaumont C: Estimation of the genetic parameters of meat characteristics and of their genetic correlations with growth and body composition in an experimental broiler line. Poult. Sci 2001, 80:839-843.

13. Sibut V, Le Bihan-Duval E, Tesseraud S, Godet E, Bordeau T, CailleauAudouin E, Chartrin P, Duclos MJ, Berri C: Adenosine monophosphateactivated protein kinase involved in variations of glycogen and breast meat quality between lean and fat chickens muscle. J. Anim. Sci 2008, 86:2888-2896.

14. Leclercq B, Blum JC, Boyer JP: Selecting broilers for low and high abdominal fat: Initial observations. Br. Poult. Sci 1980, 21:107-113.

15. Lobjois V, Liaubet L, SanCristobal M, Glenisson J, Feve K, Rallieres J, Le Roy P, Milan D, Cherel P, Hatey F: A muscle transcriptome analysis identifies positional candidate genes for a complex trait in pig. Animal Genetics 2008, 39(2):47-162.

16. Wang YH, Byrne KA, Reverter A, Harper GS, Taniguchi M, McWilliam SM, Mannen H, Oyama K, Lehnert SA: Transcriptional profiling of skeletal muscle tissue from two breeds of cattle. Mammalian Genome 2005, 16:201-210.

17. Bernard C, Cassar-Malek I, Le Cunff M, Dubroeuca H, Renand G, Hocquette JF: New indicators of beef sensory quality revealed by expression of specific genes. J. Agric. Food Chem 2007, 55(13):5229-37.

18. Ponsuksili S, Murani E, Phatsara C, Jonas E, Walz C, Schwerin M, Schellander K, Wimmers K: Expression profiling of muscle reveals transcripts differentially expressed in muscle that affect water-holding capacity of pork. J Agric. Food Chem 2008, 56(21):10311-7.

19. Ferrer JC, Favre C, Gomis RR, Fernandez-Novella JM, Garcia-Rocha M, de la Iglesia N, Cid E, Guinovart JJ: Control of glycogen deposition. FEBS Letters 2003, 546:127-132.

20. Soderling TR, Srivastava AK, Bass MA, Khatra BS: Phosphorylation and inactivation of glycogen synthase by phosphorylase kinase. Proc. Natl. Acad. Sci. USA 1979, 76(6):2536-40.

21. Croniger CM, Millward C, Yang J, Kawai Y, Arinze IJ, Liu S, Harada-Shiba M, Chakravarty K, Friedman JE, Poli V, Hanson RW: Mice with a deletion in the gene for CCAAT/enhancer-binding protein beta have an attenuated response to CAMP and impaired carbohydrate metabolism. J. Biol. Chem 2001, 276(1):629-38.

22. Kehrl JH, Sinnarajah S: RGS2: a multifunctional regulator of G-protein signaling. Int. J. Biochem. Cell Biol 2002, 34(5):432-438.

23. Anliker B, Chun J: Cell surface receptors in lysophospholipid signaling. Semin. Cell. Dev. Biol 2004, 15:457-46534.

24. Yoshida A, Ueda H: Activation of Gi1 by lysophosphatidic acid receptor without ligand in the baculovirus expression system. Biochem. Biophys. Res. Commun 1999, 259:78-84.
25. Cheung PC, Salt IP, Davies SP, Hardie DG, Carling D: Characterization of AMP-activated protein kinase gamma-subunit isoforms and their rôle in AMP binding. Biochem J 2000, 3:659-669.

26. McBride A, Ghilagaber S, Nikolaev A, Hardie DG: The glycogen-binding domain on the AMPK beta subunit allows the kinase to act as a glycogen sensor. Cell Metab 2009, 9(1):23-34.

27. Houten SM, Chegary M, Te Brinke H, Wijnen WJ, Glatz JF, Luiken J J, Wijburg FA, Wanders RJ: Pyruvate dehydrogenase kinase 4 expression is synergistically induced by AMP-activated protein kinase and fatty acids. Cell. Mol. Life Sci 2009, 66(7):1283-94.

28. Stoppani J, Hildebrandt AL, Sakamoto K, Cameron-Smith D, Goodyear LJ Neufer PD: AMP-activated protein kinase activates transcription of the UCP3 and HKII genes in rat skeletal muscle. Am J Physiol Endocrinol Metab 2002, 283(6):E1239-48.

29. Putman CT, Kiricsi M, Pearcey J, MacLean IM, Bamford JA, Murdoch GK, Dixon WT, Pette D: AMPK activation increases uncoupling protein-3 expression and mitochondrial enzyme activities in rat muscle without fibre type transitions. J Physiol 2000, 551(Pt 1):169-78.

30. Joubert R, Métayer Coustard S, Swennenb Q, Sibut V, Crochet S, CailleauAudouin E, Buyse J, Decuypere E, Wrutniak-Cabello C, Cabello G, Tesseraud S, Collin A: The beta-adrenergic system is involved in the regulation of the expression of avian uncoupling protein in the chicken. Domest. Anim. Endocrinol 2009, 38(2):115-125.

31. Parker GE, Pederson BA, Obayashi M, Schroeder JM, Harris RA, Roach PJ: Gene expression profiling of mice with genetically modified muscle glycogen content. Biochem J 2006, 395(1):137-45.

32. Pederson BA, Chen HY, Schroeder JM, Shou WN, DePaoli-Roach AA, Roach PJ: Abnormal cardiac development in the absence of heart glycogen. Mol. Cell. Biol 2004, 24(16):7179-7187.

33. Manchester J, Skurat AV, Roach P, Hauschka SD, Lawrence JC: Increased glycogen accumulation in transgenic mice overexpressing glycogen synthase in skeletal muscle. PNAS 1996, 93(20):10707-10711.

34. Nilsson EC, Long YC, Martinsson S, Glund S, Garcia-Roves P, Svensson LT, Andersson L, Zierath JR, Mahlapuu M: Opposite transcriptional regulation in skeletal muscle of AMP-activated protein kinase gamma3 R225Q transgenic versus knock-out mice. J. Biol. Chem 2006, 281(11):244-52.

35. Dalrymple RH, Hamm R: A method for extraction of glycogen and metabolites from a single muscle sample. J. Food Technol 1973, 8:439-444.

36. Gene expression omnibus. [http://www.ncbi.n/m.nih.gov/projects/geo/].

37. Klopp C, Moreews F, Aubry M, Lagarrigue S: Contribution to the annotations of the Chicken $20 \mathrm{~K}$ oligo microarray of ARKGenomics. Plant \& Animal Genomes XVI Conference: January 12-16 2008.

38. Genepix User's guide and tutorial. [http://www.soe.ucsc.edu/classes/ bme210/Spring07/GenePix_Pro_6.0_Manual_RevL.pdf].

39. Anapuce 2.0 download and tutorial. [http://www.agroparistech.fr/mia/ doku.php?id=productions:logiciels\#anapuce2.0].

40. Benjamini $Y$, Hocheberg $Y$ : Controlling the false discovery rate - a practical and powerful approach to multiple testing. Journal of the royal statistical society seriesB- Methodological 1995, 57(1):289-300.

41. Pfaffl MW: A new mathematical model for relative quantification in realtime RT-PCR. Nucleic Acids Res 2001, 29:2003-2007.

42. Guernec A, Berri C, Chevalier B, Wacrenier-Ceré N, Le Bihan-Duval E, Duclos MJ: Muscle development, insulin-like growth factor-I and myostatin mRNA levels in chickens selected for increased breast muscle yield. Growth. Horm. IGF Res 2003, 13:8-18.

43. Quandt K, Frech K, Karas H, Wingender E, Werner T: Matlnd and Matlnspector: new fast end versatile tools for detection of consensus matches in nucleotide sequence data. Nucleic Acid Res 1995, 23:4878-84.

44. Cartharius K, Frech K, Grote K, Klocke B, Haltmeier M, Klingenhoff A, Frisch M, Bayerlein M, Werner T: Matlnspector and beyond: promoter analysis based on transcription factor binding sites. Bioinformatics 2005 , 21:2933-42.

doi:10.1186/1471-2164-12-112

Cite this article as: Sibut et al:: Identification of differentially expressed genes in chickens differing in muscle glycogen content and meat quality. BMC Genomics 2011 12:112. 